\title{
EVIDENCIAÇÃO DE INFORMAÇÕES POR SEGMENTO DE NEGÓCIOS: ESTUDO COM EMPRESAS BRASILEIRAS, ALEMÃS, FRANCESAS E NORTE-AMERICANAS DO SETOR DE SIDERURGIA E METALURGIA ${ }^{1}$
}

\section{EVIDENTIATION OF INFORMATION BY BUSINESS SEGMENT: STUDY WITH BRAZILIAN, GERMAN, FRENCH AND NORTH AMERICAN COMPANIES OF THE STEEL AND METALLURGY SECTOR}

\author{
Bibiana Fraga Gonçalves \\ Bacharel em Ciências Contábeis pela Universidade do Vale do Rio dos Sinos - Unisinos \\ Universidade do Vale do Rio dos Sinos - Unisinos \\ bibiana.goncalves21@hotmail.com \\ Marcos Antônio de Souza \\ Doutor em Controladoria e Contabilidade pela Universidade de São Paulo \\ Professor da Universidade Federal de Uberlândia (UFU) \\ marcos.souza1@ufu.br
}

Débora Gomes de Gomes

Doutora em Ciências Contábeis

Professora da Universidade Federal do Rio Grande - FURG

debora furg@yahoo.com.br

Marcia Bianchi

Universidade Federal do Rio Grande do Sul

doutorado em Economia pela Universidade Federal do Rio Grande do Sul - UFRGS

marcia.bianchi@ufrgs.br

\begin{abstract}
RESUMO
Objetivo: O objetivo do estudo foi analisar o nível de evidenciação de empresas brasileiras, alemãs, francesas e norte americanas do setor de siderurgia e metalurgia, comparativamente às exigências do IFRS 8 quanto à publicação por segmentos de negócios.

Fundamento: A globalização dos negócios e dos mercados, mesmo que relativa, trouxe a necessidade de harmonização mundial da linguagem contábil, surgindo daí a criação do IASB, órgão de normatização independente e responsável pela emissão das IFRS. De forma análoga, há a preocupação de ampliar e melhor qualificar a evidenciação de informações contábeis ao mercado, destacando-se neste estudo aquelas referentes às publicações por segmentos de negócios.
\end{abstract}

\footnotetext{
${ }^{1}$ Artigo recebido em: 15/03/2019. Revisado por pares em: 27/05/2019. Recomendado para publicação: 15/08/2019 por Luiz Felipe de Araújo Pontes Girão (Editor Adjunto). Publicado em: 02/09/2019. Organização responsável pelo periódico: UFPB
} 
Método: Trata-se de uma pesquisa documental, exploratória, de caráter descritivo e qualiquantitativo. Aplicou-se a análise de conteúdo nos relatórios das demonstrações contábeis do exercício de 2015, de companhias listadas na Bolsa de Valores de Frankfurt, BM\&FBovespa, Euronext Paris e Bolsa de Valores de Nova York.

Resultados: Os achados mostram que $24 \%$ das 33 empresas pesquisadas não apresentam informações por segmento. Os níveis de evidenciação das empresas situam-se em 79\%, 63\%, 76\% e $66 \%$ pelas empresas alemãs, brasileiras, francesas e norte-americanas, respectivamente. Observa-se que as empresas brasileiras têm ainda um largo espaço para evoluir em relação às empresas dos outros países.

Contribuições: Quanto ao mercado, a contribuição destaca aquelas categorias menos presentes na evidenciação, as quais podem ser críticas na decisão de analistas e investidores. Quanto ao meio acadêmico, destaca-se um conteúdo conceitual para as disciplinas de evidenciação contábil e auditoria e nos respectivos procedimentos práticos para evidenciação (pelas empresas informantes) e serviços de revisões (pelas empresas de auditoria).

Palavras-chave: Segmento de Negócios. Normas Contábeis Internacionais. Evidenciação Contábil. IFRS 8.

\section{ABSTRACT}

Objective: This research aimed to analyze the level of disclosure of Brazilian, German, French and North American companies in the steel and metallurgy sector, comparatively to the requirements of IFRS 8 for publication by segments.

Background: The globalization of business and markets, even if relative, brought the need for global harmonization of the accounting language, arising from the creation of the IASB, an independent standardization body and responsible for issuing IFRS. Similarly, there is a concern to broaden and better qualify the disclosure of accounting information given to the market, highlighting in this study those referring to information by business segments.

Method: This is a documental, exploratory, descriptive and quali-quantitative research. We applied the content analysis of the reports of the financial statements of 2015 of companies listed on the stock exchange of Frankfurt, BM\&FBovespa, Euronext Paris and the New York Stock Exchange.

Results: The findings showed that $24 \%$ of the 33 companies surveyed did not present information per segment. The levels of disclosure of companies were $79 \%, 63 \%, 76 \%$ and $66 \%$ by German, Brazilian, French and North American companies, respectively. Brazilian companies still have a lot to evolve in relation to companies from other countries.

Contributions: For the market, the contribution highlights those categories less present in the disclosure, which can be critical in the decision of analysts and investors. For the academic environment, the contribution highlights a conceptual content for the disciplines of accounting and auditing and their practical procedures for disclosure (by the informants' companies) and review services (by the audit firms).

Keywords: Business Segment. International Accounting Standards. Accounting Evidence. IFRS 8.

\section{INTRODUÇÃO}

A necessidade de harmonização mundial da linguagem contábil redundou, em 1973, na criação do International Accounting Standard Board (IASB), órgão de normatização independente e responsável pela emissão das International Financial Reporting Standard (IFRS), destinadas à busca de padrões e convergências às normas contábeis internacionais (Ferreira, 2011). Fajardo (2007) 
destaca que as IFRS objetivam proporcionar aos usuários das demonstrações contábeis informações consistentes, comparáveis, confiáveis e com maior nível de transparência na divulgação pelo mundo. Visando ampliar as relações comerciais, atraindo o interesse de investidores de outros países por meio de informações comparáveis e confiáveis, as IFRS têm sido reconhecidas por vários países. A comunidade europeia adotou integralmente as normas do IASB através do Regulamento 1.606/2002 e, desde então, há uma aceleração na convergência, reconhecendo as vantagens da adoção de um conjunto de normas preparadas pelo IASB, aceito oficialmente pelas empresas europeias. (Ernst Young \& Fipecafi, 2009; Parlamento Europeu, 2002; Pacter, 2016).

No Brasil, a preocupação com a convergência às IFRS culminou, em 2005, na criação do Comitê de Pronunciamentos Contábeis (CPC). Esse Comitê é o órgão responsável pela emissão de normas e orientações contábeis em concordância aos padrões internacionais de contabilidade emitidos pelo IASB. (Conselho Federal de Contabilidade - CFC, 2005).

Dentre as normas internacionais de contabilidade tem-se a que exige a evidenciação de informações por segmentos, o IFRS 8. Essa norma resulta da convergência entre as normas IAS 14 Relatórios por Segmento e SFAS 131 - Divulgações sobre Segmentos de uma Empresa e Informações Relacionadas, emitida pelo FASB, tradicional organismo dos EUA, também em 1997. (IASB, 2006). O IFRS 8, então emitido no âmbito do agora IFRS, procura assegurar aos usuários externos o acesso a informações que asseguram o objetivo fundamental da contabilidade, que é a transparência das demonstrações contábeis. Desta forma, a divulgação das informações deve ser feita com a visão e abordagem da gerência da companhia, harmonizando a contabilidade financeira com a gerencial. (Weschenfelder \& Mazzioni, 2014). Convém lembrar, entretanto, que: (1) os pronunciamentos do IASB precisam ser aderentes à Estrutura Conceitual do órgão; (2) Conforme essa estrutura conceitual, não há qualquer perspectiva dos pronunciamentos daquele órgão em relação aos usuários internos e sim aos externos. No Brasil, a publicação das atividades de negócios é requerida por meio do CPC 22 - informações por segmento, correlacionado à norma internacional de contabilidade IFRS 8 (CPC 22, 2009).

Frente ao exposto, e dada a citada norma, este estudo norteia-se pelo seguinte problema de pesquisa: Qual o nível de evidenciação adotado por empresas do Brasil, Alemanha, França e Estados Unidos com relação à norma IFRS 8? Assim, o objetivo é verificar, de forma comparativa, o nível de evidenciação nas demonstrações contábeis divulgadas por empresas do Brasil, em relação às da Alemanha, França e EUA tendo em vista as determinações da norma IFRS 8. Dados os argumentos em favor da emissão dessa norma, conhecer a adesão dada por empresas é uma forma de aferir a efetividade do seu reconhecimento prático. De forma subjacente a esse objetivo de pesquisa, há também a possibilidade de se identificar e esclarecer qual a relevância de se oferecer tal nível de conhecimento aos usuários que é dada pelas empresas ao reconhecerem tal norma do IASB. Ou seja, a relevância dada pela norma é reconhecida pelas empresas? Ela é entendida como importante para atrair investidores? Por ser o pleno cumprimento da norma uma ação que possibilita às empresas atraírem investidores, esta pesquisa também pode contribuir para verificar o grau de busca de competitividade e atratividade das empresas brasileiras, no mercado de capitais, comparativamente às empresas alemãs, francesas e norte-americanas, no que diz respeito a um maior ou menor nível de evidenciação sobre seus negócios.

O tema, informações por segmento, tem despertado o interesse de pesquisadores que buscam avaliar o nível de disclosure, a relevância e as características gerenciais das demonstrações contábeis no âmbito das informações segmentadas. Entre os estudos que buscam analisar o nível 
de evidenciação há Nichols, Street e Cereola (2012) na Europa, Kang e Gray (2013) na Austrália, Franzen e Weissenberger (2015) na Alemanha, Cruz, Machado, Oleiro e Carvalho (2011); Silva e Pinheiro (2012); Aillón, Silva, Pinzon e Wuerges (2013); Weschenfelder e Mazzioni (2014); Pinheiro e Boscov (2015) no Brasil. Tais estudos buscam identificar o nível de disclosure pelos países analisados, fato que justifica esta pesquisa por abordar a comparação do nível de evidenciação no Brasil, Alemanha, França e Estados Unidos. Contribui, assim, com a discussão do nível de aderência ao IFRS 8 no Brasil em relação aos outros países pesquisados.

Apesar dos vários estudos citados, os resultados são desencontrados, inclusive em relação ao posicionamento das empresas de auditoria independente no exame e avaliação do cumprimento da norma estabelecida. Analisar os vários patamares de adesão, aspectos com adoção em níveis diferenciados, ou mesmo não adotados, suas semelhanças e diferenças, assim como o posicionamento das empresas de auditorias, possibilitam que este estudo agregue um conjunto de constatações e conhecimentos até então desconhecidos ou, pelo menos, motivadores a que outras pesquisas semelhantes sobre essa temática sejam realizadas.

Quanto ao aspecto setorial, a escolha pelo setor de metalurgia e siderurgia pauta-se pela importância que o segmento representa no cenário econômico e social nos países pesquisados. Esta pesquisa limita-se quanto a um plano temporal, dado que as informações coletadas se referem às demonstrações contábeis anuais publicadas e referentes ao exercício de 2015, e pela diferença de calendário fiscal de cada país. Nesse sentido, observa-se que nem todas as demonstrações contábeis possuem encerramento no mês de dezembro, mas, de outra parte, todas correspondem ao final do mesmo exercício de 2015.

\section{REVISÃO DE LITERATURA}

\subsection{Evidenciação Contábil}

O processo de evidenciação contábil (ou disclosure) é uma área de pesquisa interdisciplinar, incorporando, assim, particularidades de distintas áreas. Esse entendimento dado por (Verrecchia, 2001) está implícito no estudo de Suzart (2016), para o qual a evidenciação tem o objetivo de divulgar informações de uma determinada entidade, a respeito da sua estrutura patrimonial, e do fluxo financeiro originado por suas atividades e decisões tomadas pelos seus gestores no decorrer de um exercício. Assim como tratado por Lopes e Beuren (2017), os termos evidenciação, disclosure e divulgação são usados como sinônimos no presente estudo.

A atividade contábil, apesar da abrangência e possibilidades de execução, inerentes ao seu exercício, exige atenção para determinadas particularidades, como ocorre com a evidenciação, dada a sua relação e impacto nas decisões tomadas pelos seus usuários, assim como de reduzir a assimetria informacional (Hendriksen \& Van Breda, 1999). Uma das questões principais que surge no tema evidenciação é determinar a quais usuários destinam-se as informações, o que inclui considerar também qual a finalidade delas (Hendriksen \& Van Breda, 1999). Apesar da necessidade de evidenciar-se, tanto informações obrigatórias, como voluntárias, é necessário destacar que a essência é a mesma, ou seja, servir os usuários da informação contábil.

Pesquisadores como Hendriksen e Van Breda (1999) advogam que uma adequada divulgação deve basear-se no benefício que oferece ao bem-estar social, o que dificulta que a evidenciação tenha um nível de alcance que alcance e/ou contemple a todos os usuários na mesma dimensão. O que predomina, conforme os autores, vem no sentido de que os usuários tomam decisões fundamentado naquilo que é evidenciado pelas empresas e, devido a isso, necessitam de informações disponibilizadas de forma geral e não isolada, mesmo não conseguindo contemplar as necessidades desses em toda a sua amplitude. Segundo Suzart (2016, p. 54), duas categorias 
identificam a evidenciação de informações contábeis: (a) informações obrigatórias, que se referem ao "conjunto mínimo de informações contábeis que uma entidade deve divulgar compulsoriamente, para não sofrer sanções por parte dos órgãos reguladores"; (b) informações voluntárias, que se referem ao "conjunto de informações contábeis que é divulgado livremente por uma entidade, sem que haja uma norma que lhe obrigue a realizar tal divulgação".

Um dos tópicos mais recentes desenvolvidos sobre a evidenciação é a necessidade de as empresas atenderem novas normativas contábeis (IASB e CPC), mais especificamente relacionadas às informações adicionais sobre seus principais segmentos de negócio. $\mathrm{O}$ objetivo é proporcionar aos diversos usuários informações ampliadas e que lhes possibilitem maior segurança em suas análises e decisões sobre investimentos.

\subsection{A Norma de Informações por Segmento}

A norma internacional de contabilidade IFRS 8 surgiu em novembro de 2006 em meio ao projeto de convergência de curto prazo entre IASB e FASB, buscando minimizar as diferenças entre as IFRSs e os US GAAPs. Assim, o IASB considerou o Pronunciamento SFAS 131 Divulgações sobre Segmento de uma Empresa e Informações Relacionadas, emitida em 1997 pelo FASB, comparando-o com a IAS 14 - Relatório por Segmento emitido pelo IASC em 1997. (IASB, 2006). Assim, ambas as normas, IFRS 8 e SFAS 131, objetivaram incluir nos relatórios financeiros informações internas de alta qualidade.

A aplicação da IFRS 8 se iniciou em $1^{0}$ de janeiro de 2009, sendo permitida a sua aplicação antecipada, devendo a entidade divulgar tal ocorrência por meio das notas explicativas. Caso a organização não esteja obrigada a adotar tal a norma, mas opte por divulgar informações pertinentes, não poderá descrever as informações como sendo por segmento. (Mourad, 2009).

Conforme estabelece a norma IFRS 8, a evidenciação deve identificar os segmentos operacionais envolvidos, tomando como base os relatórios internos que são avaliados regularmente pelo principal tomador de decisões operacionais da organização para aplicar recursos ao segmento e avaliar seu desempenho. Um segmento operacional é definido como um componente de uma entidade com atuação em atividades de negócios que geram receitas e incorrem custos e despesas, cujos resultados operacionais sejam avaliados pelo principal gestor do segmento e que possua informações financeiras distintas dos demais segmentos.

Boscov (2009, p. 46) acrescenta que "A norma do IASB apresenta limites quantitativos que devem ser considerados por uma entidade na escolha de quais segmentos devem ser divulgados. Há o teste dos $10 \%$ para receita, resultado e ativo, e o teste dos $75 \%$ para receitas externas.". No entanto, se houver segmentos operacionais que não atinjam tais limites os mesmos podem ser reportados pela organização, caso a administração entenda que a informação sobre tais segmentos seja relevante aos usuários das demonstrações contábeis. (IASB, 2006). No âmbito nacional, o Brasil regulamenta esse procedimento por meio do Pronunciamento Técnico CPC 22, aprovado em 26/06/2009 e divulgado em 31/07/2009.

Algumas restrições a um maior nível de evidenciação por segmento são identificadas por Ferreira, Souza, Guerra e Mariano (2018), os quais argumentam que os pontos favoráveis em relação à divulgação de demonstrações por segmento podem ser resumidos em riqueza de informações geradas. Por outro lado, há também pontos desfavoráveis, sendo o principal deles a sensação de se estar expondo a empresa a seus concorrentes.

Apesar da propriedade das discussões sobre os pronunciamentos oficiais, é necessário ter como foco a relevância que a informação por segmento pode ter para os investidores ou para outros usuários da informação contábil. É certo que, quando organismos como IASB e FASB discutem determinados assuntos, o pressuposto é sempre o daquela relevância. Não obstante, esse aspecto do usuário externo deve ser realçado em trabalhos dessa natureza. 


\subsection{Estudos Relacionados a Informações por Segmento}

Diversos estudos têm sido desenvolvidos ao longo do tempo sobre a divulgação de informações por segmento (Figura 1). Apesar desses estudos apresentarem níveis aceitáveis de evidenciação, deve-se destacar que em todos eles há destaque para informações não evidenciadas de forma extensiva. Cruz et al. (2011) citam a fragilidade de informações sobre clientes (também destacado por Fath, Gauski, Oro \& Scott, 2015), além da falta do fluxo de caixa por segmento, também retratada por Weschenfelder e Mazzioni (2014). Essa fragilidade sobre informações de clientes também é identificada por Aillón et al. (2013).

Ferreira et al. (2018) ressaltam que não há diferenças relevantes entre a evidenciação de empresas mais lucrativas em relação às demais. Esse resultado contraria uma premissa do estudo, ou seja, que empresas deficitárias apresentariam níveis elevados ou diferenciados de evidenciação como forma de melhorar apresentar e atenuar os resultados. A análise dos demais estudos sobre o tema mantém a característica de realçar aspectos do CPC 22 não atendidos nas respectivas publicações.

Figura 1 - Estudos sobre Informações por Segmento no Brasil

\begin{tabular}{|c|c|}
\hline Autoria & Principais achados \\
\hline Boscov (2009) & $\begin{array}{l}\text { As informações gerenciais promovem maior nível de disclosure e melhorias nas decisões } \\
\text { econômicas, projeções e aumento no poder de negociação da empresa. }\end{array}$ \\
\hline Cruz et al. (2011) & $\begin{array}{l}\text { A divulgação ainda é restrita no cenário brasileiro. Além disso, há escassez de informações por } \\
\text { clientes e falta do fluxo de caixa por segmento. }\end{array}$ \\
\hline Silva e Pinheiro (2012) & $\begin{array}{l}\text { O nível de evidenciação encontrado foi de } 63 \% \text {. Há grande dispersão de evidenciação entre os } \\
\text { setores, sendo as empresas de materiais básicos as de maior adesão. }\end{array}$ \\
\hline Aillón et al. (2013) & $\begin{array}{l}\text { A evidenciação é distinta entre os setores: mineração com maior divulgação e com menor o de } \\
\text { software e dados. Há reduzido nível de disclosure por área geográfica e por nível de clientes. }\end{array}$ \\
\hline $\begin{array}{l}\text { Schvirck, Lunkes e } \\
\text { Gasparetto (2013) }\end{array}$ & $\begin{array}{l}\text { Há empresas que não fazem referência a informações por segmentos; } 27 \% \text { delas possuem } \\
\text { apenas um segmento; há grande heterogeneidade nas estruturas dos relatórios. }\end{array}$ \\
\hline $\begin{array}{l}\text { Weschenfelder e } \\
\text { Mazzioni (2014) }\end{array}$ & $\begin{array}{l}\text { Companhias que possuem ADR's tendem a evidenciar menos informações por segmento. } \\
\text { Algumas não citam o CPC } 22 \text { nas demonstrações e nenhuma evidenciou a Demonstração dos } \\
\text { Fluxos de Caixa (DFC) por segmento. Poucas citaram a relevância dos principais clientes. }\end{array}$ \\
\hline $\begin{array}{l}\text { Mapurunga, Ponte e } \\
\text { Holanda (2014) }\end{array}$ & $\begin{array}{l}\text { Baixo grau de evidenciação por segmento. O porte das companhias, a empresa de auditoria e a } \\
\text { governança corporativa impacta positivamente no grau de evidenciação. No entanto, } \\
\text { rentabilidade, endividamento e internacionalização não provocam esse efeito. }\end{array}$ \\
\hline $\begin{array}{l}\text { Almeida, Silva, Alves } \\
\text { e Oliveira (2015) }\end{array}$ & $\begin{array}{l}\text { O nível de adequação das empresas é influenciado pelo tamanho do ativo. Há reduzido nível } \\
\text { de adequação das empresas às exigências do CPC } 22 .\end{array}$ \\
\hline $\begin{array}{l}\text { Oliveira, Costa e } \\
\text { Avila (2015) }\end{array}$ & $\begin{array}{l}\text { Prevalece a divulgação de segmentos por linhas de negócios, entre } 2 \text { e } 4 \text { segmentos. O índice de } \\
\text { evidenciação observado foi de } 63 \% \text { sendo que as companhias com Retorno Sobre o Ativo (ROA) } \\
\text { acima da média do setor disponibilizam menos informações. }\end{array}$ \\
\hline Fath et al. (2015) & $\begin{array}{l}\text { Adequada evidenciação pela maioria das empresas em relação a produtos, receitas, custos e } \\
\text { resultados. Algumas empresas têm reduzido nível de divulgação referente a principais clientes, } \\
\text { gestor e áreas geográficas, uma tendência a ocultar informações estratégicas. }\end{array}$ \\
\hline Ferreira et al. (2018) & $\begin{array}{l}\text { Não há diferenças significativas na evidenciação de ambos os grupos de empresas (lucrativas e } \\
\text { deficitárias), contrariando a expectativa do estudo de que empresas com prejuízo apresentariam } \\
\text { níveis elevados ou diferenciados de evidenciação como forma de melhor apresentar seus } \\
\text { resultados. }\end{array}$ \\
\hline
\end{tabular}

Fonte: Autores citados.

Dado o conteúdo dos estudos apresentados na Figura 1, o que se observa como contribuição deste estudo, em relação a eles, é a abrangência de empresas de outros países, o que pode trazer informação diferenciada e até então não abordada. Além disso, optou-se também por analisar os relatórios de auditoria para aferir como os pareceres tratam a regularidade no 
atendimento dedicado pelas empresas. Como já destacado anteriormente, essa ação (analisar os pareceres) surgiu do reconhecimento de que o principal usuário da informação contábil são os acionistas e demais usuários externos à empresa. E o parecer da auditoria independente é um dos importantes instrumentos por eles acessados.

\section{METODOLOGIA}

Quanto à finalidade esta pesquisa classifica-se como qualitativa, conforme pressupostos de Oliveira (1999), dado que gera conhecimentos que visam contribuir com a melhora do saber sobre o nível de evidenciação por segmentos. também se classifica como quantitativa, segundo Martins e Theóphilo (2007), por se utilizar de instrumentos de mensuração e análise quantitativos. O caráter de estudo descritivo também se apresenta, de acordo com o proposto por Gil (2010), ao descrever as características da publicação dos segmentos por companhias constantes na amostra, expondo o nível de evidenciação das informações segmentadas de empresas que operam na bolsa de valores dos respectivos países de origem. Por fim tem o caráter de uma pesquisa documental, pois os dados são obtidos por meio de documentos, na sua forma original e ainda sem qualquer tratamento específico de análise pregressa (Marconi \& Lakatos, 2010). Os documentos utilizados neste estudo são as demonstrações contábeis de 2015 das empresas pesquisadas, os únicos disponíveis na época da coleta: $1^{\underline{0}}$ semestre de 2017.

Esta pesquisa contempla uma amostra não probabilística, circunscrita às empresas do segmento de metalurgia e siderurgia listadas nas bolsas BM\&FBovespa, Bolsa de Valores de Frankfurt, Bolsa de Valores de Nova York (NYSE) e na Euronext Paris, negociadas no Brasil, Alemanha, EUA e França, as principais dos países, respectivamente. A seleção destes países devese a importância que detém na economia global, estando entre as dez maiores economias (International Monetary Fund, 2015). Outros países poderiam ser considerados na pesquisa, sendo esta uma das suas limitações, mas optou-se por incluir aqueles de maior acessibilidade, principalmente por se considerar uma pesquisa feita a partir do Brasil. A representatividade econômica e social do setor de metalurgia e siderurgia (Wordsteel Association, 2015) foi fator relevante para sua escolha. A escolha desse setor deve-se também à sua pujança nas atividades dos países pesquisados. Isso não significa, obviamente, que outros segmentos de negócios não possam ser considerados em futuras pesquisas. Isso seria salutar, pois poderia permitir análises comparativas mais robustas.

Em razão do objetivo de analisar o nível de aderência das empresas brasileiras, alemãs, norte americanas e francesas a respeito da aplicação da IFRS 8, e visando possibilitar a comparabilidade entre os países, excluiu-se da amostra as empresas que apesar de listadas diferem da nacionalidade da bolsa de valores analisada.

A relação completa das companhias que compõem a amostra utilizadas neste estudo contempla 11 empresas brasileiras (33\% da amostra), oito empresas alemãs (18\%), duas empresas francesas $(6 \%)$ e 14 empresas americanas (43\%). As demonstrações contábeis foram obtidas através do homepage da BM\&FBovespa, Bolsa de Valores de Frankfurt, Bolsa de Valores de Nova York (New York Stock Exchange - NYSE) e na Euronext Paris. Para as demonstrações contábeis não disponibilizadas na homepage das bolsas de valores foram realizadas buscas nos websites das empresas e da homepage do órgão fiscalizador das companhias de capital aberto de cada país.

A verificação dos dados ocorreu pela análise de conteúdo. Trata-se de uma técnica de investigação que visa interpretar os dados por meio de uma descrição objetiva, sistemática e quantitativa do conteúdo. Martins e Theóphilo (2007) acrescentam que para a análise de conteúdo devem ser obedecidas três etapas: (a) pré-análise, etapa de coleta e organização dos dados; (b) descrição analítica, utilização do referencial teórico para o profundo estudo dos documentos; (c) interpretação inferencial, etapa final na qual os resultados são revelados com quadros de 
referência. Assim, de posse das notas explicativas analisou-se a evidenciação das informações por segmento, utilizando-se para tanto as 19 categorias da norma IFRS 8 (Figura 2).

Figura 2 - Itens para a Análise das Informações por Segmento

\begin{tabular}{|c|c|c|}
\hline Categoria & IFRS 8 & $\begin{array}{r}\text { Parágrafo } \\
\text { da norma }\end{array}$ \\
\hline 1 & Mencionou os fatores utilizados para identificar os segmentos? & $22 \mathrm{a}$ \\
\hline 2 & Mencionou tipos de produtos e serviços dos quais cada segmento obtém receita? & $22 \mathrm{~b}$ \\
\hline 3 & A divulgação é comparada com o ano anterior? & 17 \\
\hline 4 & Evidenciou os ativos por segmento? & 23 \\
\hline 5 & Evidenciou os passivos por segmento? & 23 \\
\hline 6 & Evidenciou as receitas por segmento? & $23 \mathrm{a}$ \\
\hline 7 & Evidenciou as receitas de transações com outros segmentos da mesma entidade? & $23 \mathrm{~b}$ \\
\hline 8 & Evidenciou receitas e despesas financeiras? & $23 \mathrm{c}, \mathrm{d}$ \\
\hline 9 & Evidenciou depreciação e amortização? & $23 \mathrm{e}$ \\
\hline 10 & Evidenciou o resultado de coligadas pela equivalência patrimonial? & $23 \mathrm{~g}$ \\
\hline 11 & Divulgou a despesa ou receita com imposto sobre o lucro por segmento? & $23 \mathrm{~h}$ \\
\hline 12 & Evidenciou o lucro ou prejuízo por segmento? & 23 \\
\hline 13 & Apresentou conciliação entre receitas dos segmentos com as receitas totais & $28 \mathrm{a}$ \\
\hline 14 & Apresentou conciliação entre o resultado por segmento e resultado da entidade? & $28 \mathrm{~b}$ \\
\hline 15 & Apresentou conciliação entre o total dos ativos dos segmentos com os ativos da entidade? & $28 \mathrm{c}$ \\
\hline 16 & $\begin{array}{l}\text { Apresentou conciliação entre o total dos passivos dos segmentos com os passivos da } \\
\text { entidade? }\end{array}$ & $28 \mathrm{~d}$ \\
\hline 17 & Evidenciou se possui clientes com representatividade maior de $10 \%$ da receita total? & 34 \\
\hline 18 & $\begin{array}{l}\text { Evidenciou informações sobre áreas geográficas de receitas provenientes de clientes } \\
\text { externos? }\end{array}$ & $33 \mathrm{a}$ \\
\hline 19 & Evidenciou informações sobre áreas geográficas de ativos não circulantes? & $33 \mathrm{~b}$ \\
\hline
\end{tabular}

Fonte: Adaptado de Aillón et al. (2013) e Weschenfelder e Mazzioni (2014).

Foi atribuído o valor um (1) para cada item que consta na Figura 2 e que tenha sido apresentado pela empresa. Em caso de inexistência de informação ou falta de conformidade com a norma foi atribuído o valor zero (0). Após a codificação dos dados utilizou-se planilha eletrônica para tabular os dados, a fim de analisá-los estatisticamente por meio de medida de tendência central, variabilidade (desvio-padrão) e testes de correlação.

Mesmo se reconhecendo que nem todas as empresas pesquisadas são obrigadas a atender a todos os requisitos de evidenciação estabelecidos pela norma, optou-se mesmo assim em fazer um ranking entre elas com a finalidade de viabilizar alguma forma de análise comparativa. Estudos posteriores poderão focalizar esse aspecto e trazer uma contribuição adicional a este estudo. De outra parte, mesmo com tal limitação, e por se tratar de um estudo exploratório, entende-se que esta pesquisa oferece contribuição por oferecer uma medida de grandeza que poderá no futuro motivar outras pesquisas sobre essa temática.

\section{RESULTADOS}

As companhias que fizeram parte deste estudo atuam no segmento de siderurgia e metalurgia, cujas sedes administrativas estão situadas na Alemanha, Brasil, Estados Unidos da América e França e que possuem títulos negociados na Bolsa de Valores de Frankfurt, BM\&FBovespa, Bolsa de Valores de Nova York e na Euronext Paris, respectivamente. Por tratar de um segmento específico de negócio (siderurgia \& metalurgia), ocorre desbalanceamento amostral, tratado em análise específica. Quando aplicável adotou-se medidas de equiparação, como a média ponderada, visando atenuar os seus efeitos. 


\subsection{Quadro Geral da Evidência pelas Empresas}

Mediante o uso da análise de conteúdo verificou-se que das 33 companhias, 25 (76\%) apresentaram informações por segmento em suas notas explicativas às demonstrações contábeis de 2015 , conforme pode ser observado na Tabela 1. Nota-se que, cinco companhias, equivalente a $15 \%$ da amostra, duas brasileiras e três norte-americanas, não divulgaram as informações de seus segmentos, mas apresentaram o motivo da falta de evidenciação. Outras três companhias (9\%), duas brasileiras e uma alemã, não apresentaram as informações dos segmentos, nem fizeram qualquer referência sobre essa falta de evidenciação. Nota-se que das 33 companhias analisadas 32 tiveram em seu parecer de auditoria a informação de que as demonstrações contábeis estavam em conformidade com o IFRS ou com US GAAP, mesmo não evidenciando as informações por segmento.

Tabela 1 - Dados da Amostra

\begin{tabular}{|c|c|c|c|c|c|c|c|}
\hline \multirow[t]{2}{*}{ País } & \multirow[t]{2}{*}{$\begin{array}{c}\text { Empresas } \\
\text { da Amostra }\end{array}$} & \multicolumn{2}{|c|}{$\begin{array}{c}\text { Evidenciaram por } \\
\text { Segmento }\end{array}$} & \multicolumn{2}{|c|}{$\begin{array}{c}\text { Justificaram Falta de } \\
\text { Evidenciação }\end{array}$} & \multicolumn{2}{|c|}{$\begin{array}{c}\text { Conformidade das } \\
\text { Demonstrações com IFRS } \\
\text { \& US GAAP }\end{array}$} \\
\hline & & Sim & Não & Sim & Não & Sim & Não \\
\hline Alemanha & 6 & 5 & 1 & 0 & 1 & 5 & 1 \\
\hline Brasil & 11 & 7 & 4 & 2 & 2 & 11 & 0 \\
\hline EUA & 14 & 11 & 3 & 3 & 0 & 14 & 0 \\
\hline França & 2 & 2 & 0 & 0 & 0 & 2 & 0 \\
\hline Total & 33 & 25 & 8 & 5 & 3 & 32 & 1 \\
\hline
\end{tabular}

Fonte: Dados da Pesquisa.

As cinco empresas que explicaram o motivo da falta de evidenciação das informações por segmentos informaram possuir apenas um segmento e, desta forma, apresentar as informações por segmento seria uma simples repetição de dados. Comentaram que avaliam suas operações com base nas informações consolidadas da companhia. Para a verificação do nível de evidenciação, em relação aos aspectos mencionados pelas empresas pesquisadas, foram desconsideradas para análise de dados as cinco companhias que informaram possuir apenas um segmento, bem como as três companhias que não reportaram as informações por segmento.

A exclusão dessas oito empresas deu-se por entender que as companhias não estão em conformidade com a norma IFRS 8 , uma vez que mesmo possuindo apenas um segmento a evidenciação deve ser realizada.

\subsection{Nível de Evidenciação das Informações por Segmento}

Verificou-se, com base nas 19 categorias listadas na Figura 2, o nível de evidenciação em cada categoria. Para obtenção do nível de evidenciação por país calculou-se a média entre as Companhias que divulgaram a informação e o total de companhias da amostra de cada país.

A Tabela 2 apresenta o grau de evidenciação de cada categoria solicitado na norma IFRS 8, cujo total da amostra revela a média ponderada pela quantidade de empresas que compõe a amostra. Já o total por país é calculado pela média aritmética. Com esses procedimentos procurouse atenuar os efeitos provocados pelo desbalanceamento da amostra. Para facilitar a análise, as 
categorias foram organizadas em ordem alfabética. O grau de evidenciação geral da amostra foi de $68 \%$, permitindo constatar que as companhias não estão divulgando todas as informações solicitadas pela norma. Observa-se, ainda, que 100\% das companhias alemãs, brasileiras, norteamericanas e francesas evidenciaram as receitas por segmento, o resultado do segmento e apresentaram as informações de forma comparativa com o ano anterior. Os itens menos evidenciados foram: dependência de principais clientes, com $8 \%$, e impostos sobre o lucro com $24 \%$ de evidenciação.

Tabela 2 - Nível de Evidenciação por Categoria a Ser Evidenciada (\%)

\begin{tabular}{|c|c|c|c|c|c|}
\hline Item de Divulgação & Alemanha & Brasil & EUA & França & Total Amostra \\
\hline Ativos do segmento & 60 & 71 & 91 & 100 & 79 \\
\hline Ativos NC por área geográfica & 80 & 29 & 73 & 100 & 61 \\
\hline Comparação com o ano anterior & 100 & 100 & 100 & 100 & 100 \\
\hline Conciliação das receitas & 100 & 86 & 100 & 100 & 95 \\
\hline Conciliação do lucro ou prejuízo & 100 & 86 & 91 & 50 & 88 \\
\hline Conciliação dos ativos & 60 & 71 & 91 & 50 & 76 \\
\hline Conciliação dos passivos & 60 & 57 & 9 & 50 & 37 \\
\hline Depreciação e amortização & 100 & 43 & 100 & 100 & 81 \\
\hline Identificação dos segmentos & 100 & 100 & 91 & 100 & 96 \\
\hline Impostos sobre o lucro & 0 & 43 & 9 & 100 & 24 \\
\hline Lucro ou prejuízo do segmento & 100 & 100 & 100 & 100 & 100 \\
\hline Passivos do segmento & 60 & 57 & 9 & 100 & 40 \\
\hline Receita por área geográfica & 80 & 57 & 73 & 100 & 71 \\
\hline Receitas e despesas financeiras & 80 & 43 & 9 & 50 & 36 \\
\hline Receitas por segmento & 100 & 100 & 100 & 100 & 100 \\
\hline Receitas entre os segmentos & 100 & 43 & 73 & 50 & 66 \\
\hline Representatividade de clientes & 20 & 14 & 0 & 0 & 8 \\
\hline Resultado de equivalência patrimonial & 100 & 29 & 27 & 0 & 39 \\
\hline Produtos e serviços do segmento & 100 & 71 & 100 & 100 & 90 \\
\hline Média de Evidenciação da amostra & 79 & 63 & 66 & 76 & 68 \\
\hline
\end{tabular}

Fonte: Dados da Pesquisa.

A pesquisa mostra que parcela representativa das empresas evidenciou a conciliação da receita, a forma como identificaram seus segmentos e relataram os tipos de produtos e serviços que cada segmento utiliza para geração de receitas.

A Tabela 3, apresenta a quantidade de empresas de cada país que compôs a amostra, bem como a pontuação per capita obtida por cada país, calculada pelo somatório da pontuação individual das companhias (conforme critério apresentado logo após a Figura 2), dividido pela quantidade de empresas da amostra. 
Tabela 3 - Pontuação de Evidenciação

\begin{tabular}{lcccc}
\multicolumn{1}{c}{ Dados da Pesquisa } & Alemanha & Brasil & EUA & França \\
\hline Quantidade de Companhias & 5 & 7 & 11 & 2 \\
Pontuação Per capita obtida & 15,0 & 12,0 & 12,5 & 14,4 \\
\hline
\end{tabular}

Fonte: Dados da pesquisa.

A pontuação máxima que cada empresa poderia obter em relação às categorias listadas na Tabela 3 seria de 19 pontos. Conforme consta da Figura 2, essa pontuação máxima decorre das 19 categorias de evidenciação elencadas a partir da norma IFRS 8. Os dados da Tabela 3 resultam da multiplicação da porcentagem média por país (Tabela 2) pela pontuação máxima possível (19).

O conteúdo da Tabela 3 mostra que as empresas alemãs e francesas apresentam pontuação per capita próxima, ao redor de 15 pontos cada uma, mostrando similaridade no nível geral de evidenciação entre elas. No entanto, como pode ser observado na Tabela 2, há disparidade de evidenciação entre as categorias dessas empresas. Exemplificando, a categoria imposto sobre o lucro não foi evidenciada pelas alemãs, mas foi pelas francesas. Já na categoria resultado de equivalência patrimonial sucedeu-se o inverso.

Quanto às Companhias brasileiras e norte-americanas, alcançaram cerca de 12 pontos per capita, apresentando similaridade no nível geral de evidenciação. Apesar dessa igualdade, as companhias desses países diferem no nível de evidenciação entre a categoria representatividade de cliente, que não foi informado por nenhuma norte-americana, mas o foi por $14 \%$ das brasileiras.

Para melhor compreensão do resultado global da análise, apresenta-se na Figura 3 a relação entre a pontuação total, em relação a pontuação máxima de cada país. Considerou-se como pontuação máxima a multiplicação da quantidade de empresas da amostra pelo máximo possível de 19 pontos. A pontuação obtida foi mensurada pela somatória da pontuação de todas as empresas da amostra do país analisado.

Figura 3 - Pontuação de Evidenciação das Informações por Segmento

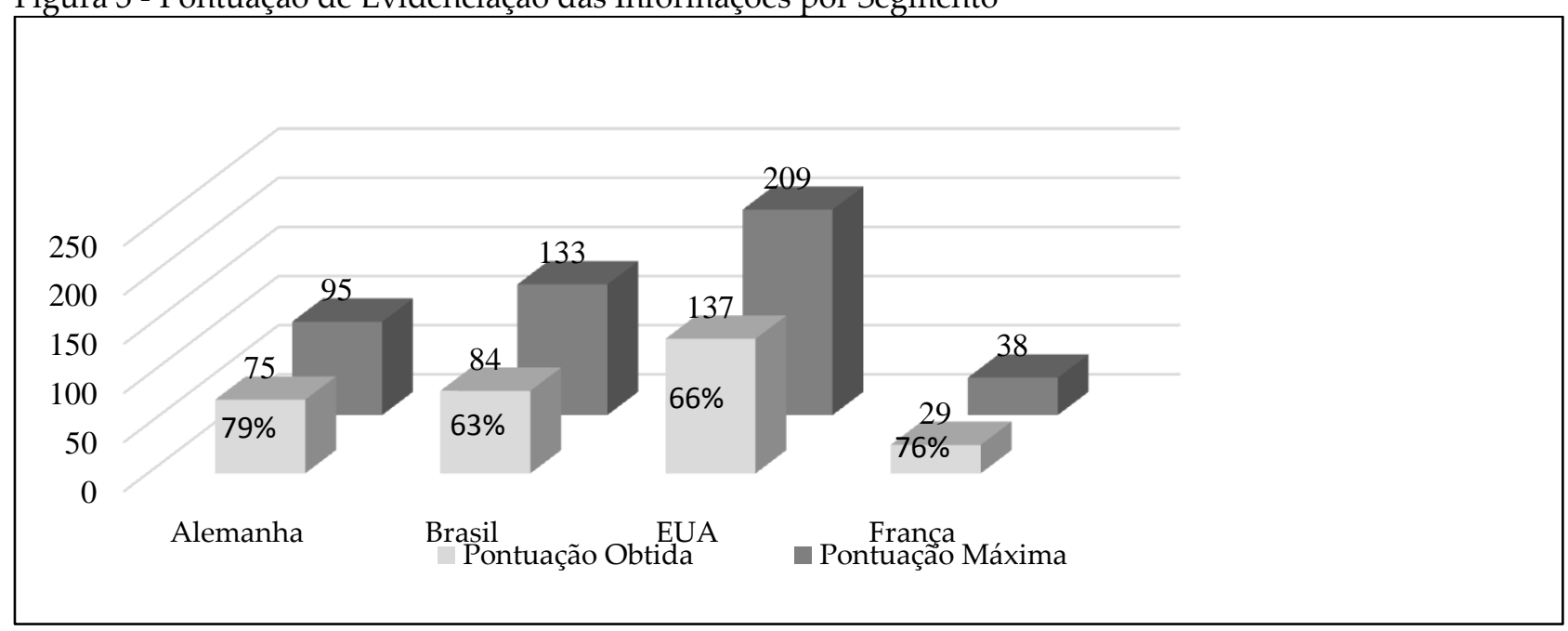

Fonte: Dados da pesquisa.

Os resultados apresentados na Figura 3 mostram que as empresas alemãs possuem maior grau de evidenciação em relação às companhias brasileiras, norte americanas e francesas, alcançando $79 \%$ da pontuação máxima. É possível constatar, ainda, que as companhias brasileiras apresentaram o menor nível de evidenciação em relação às demais, o que pode ser justificado pela 
recente adesão do Brasil às IFRS em relação aos países europeus, ou mesmo aos EUA que utiliza o US GAAP. Enfim, mesmo não havendo diferenças acentuadas as companhias brasileiras mostram menor nível de evidenciação em relação às demais.

\subsection{Estatística Descritiva}

Os dados da Tabela 4 mostram a estatística descritiva das informações por segmento pelas empresas dos respectivos países. Os resultados foram obtidos por meio da evidenciação das 19 categorias analisadas. Portanto, qualquer registro abaixo de 19 representa categorias de evidenciação não contempladas na publicação.

Tabela 4 - Resultados da Estatística Descritiva

\begin{tabular}{lcccc}
\hline & Alemanha & Brasil & EUA & França \\
\hline Média & 15 & 12 & 12 & 15 \\
Mediana & 16 & 12 & 13 & 15 \\
Moda & 17 & 18 & 13 & 1 \\
Desvio Padrão & 2 & 5 & 2 & 1 \\
Variância & 6 & 22 & 2 & 14 \\
Mínimo & 12 & 6 & 15 & 15 \\
Máximo & 17 & 18 & $13 \%$ & $5 \%$ \\
Coeficiente de Variação & $16 \%$ & $39 \%$ & &
\end{tabular}

Fonte: Dados da pesquisa.

Observa-se que, em média, as empresas alemãs apresentam 15 das 19 categorias analisadas com afastamento de 2 categorias em relação à média, conforme observado pelo desvio padrão. A variância, que evidencia o quanto cada companhia está distante da média (Larson \& Farber, 2010), indicou 6 categorias que, por meio do coeficiente de variação de $16 \%$, pode se compreender que não há um distanciamento grande entre as companhias. Isso significa, portanto, que há considerável similaridade no nível de evidenciação das empresas pesquisadas, apesar das suas diferentes origens.

As companhias brasileiras apresentaram, em média, 12 categorias com desvio padrão de 5, o maior entre as empresas dos países analisados. Observa-se, assim, que o coeficiente de variação revela uma dispersão de $39 \%$ em relação à média, mostrando a disparidade entre as companhias da amostra. O disclousure mínimo foi de 6 categorias e o máximo de 18, sendo que o mais comum foi evidenciar 18 das 19 categorias avaliadas, indicado pela respectiva moda. No entanto, metade das companhias evidenciou até 12 categorias e a outra metade divulgou acima dessa quantidade.

Em relação às companhias norte-americanas a média de evidenciação das informações por segmento foi de 12 categorias com afastamento médio de 2 categorias. No entanto, metade das companhias evidenciou mais que 13 categorias, sendo este o nível mais comum de evidenciação pelas empresas norte-americanas observado pela moda. O mínimo evidenciado foi 9 categorias e o máximo 15. Nota-se, ainda, que o coeficiente de variação obtido foi 13\% mostrando uma homogeneidade entre as empresas da amostra.

As companhias francesas evidenciaram, em média, 15 categorias com afastamento médio de 1, representando a menor baixa dispersão dentre os quatro países em relação à média, 
corroborando que há grande proximidade entre o grau de evidenciação das companhias analisadas. O mínimo evidenciado foi 14 categorias e o máximo de 15. Em virtude de apenas duas companhias francesas comporem a amostra, se observa pela mediana, que uma divulgou 15 categorias e outra 14 .

Quanto às companhias alemãs, nota-se que elas apresentaram maior nível de evidenciação por segmento em relação às demais companhias, como pode ser observado pela média de 15 . Embora as empresas francesas também tenham apresentado essa quantidade média, elas alcançaram $76 \%$ da pontuação, conforme foi apresentado no Gráfico 1, inferior às empresas alemãs que atingiram $79 \%$. As companhias brasileiras apresentaram o menor nível de evidenciação das informações por segmento, alcançando $63 \%$ da pontuação enquanto as companhias norteamericanas somaram 66\%, embora, em média, as empresas de ambos os países tenham evidenciado 12 categorias.

\subsection{Critério de Divulgação das Informações por Segmento}

A norma IFRS 8 exige que as informações por segmento sejam evidenciadas com base nos relatórios internos, utilizados pelo principal tomador de decisões para avaliar o desempenho dos segmentos. (IASB, 2006). Dentre as possibilidades, as companhias podem, em geral, evidenciar as informações das suas unidades de negócios por grupos de produtos e serviços, áreas geográficas ou clientes.

Tabela 5 - Critérios de Evidenciação das Informações por Segmento

\begin{tabular}{lccccc}
\hline \multicolumn{1}{c}{ Critério de Evidenciação } & Alemanha & Brasil & EUA & França & Total \\
\hline Produtos e serviços & 5 & 5 & 11 & 2 & $\mathbf{2 3}$ \\
Áreas geográficas & 0 & 0 & 0 & 0 & $\mathbf{0}$ \\
Área geográfica e produtos e serviços & 0 & 2 & 0 & $\mathbf{2}$ \\
\hline
\end{tabular}

Fonte: Dados da Pesquisa.

Os dados da Tabela 5 complementam o conteúdo do tópico 4.1 e Tabela 1, e mostram que 23 companhias avaliam seus segmentos por produtos e serviços e apenas duas delas, brasileiras, acompanham as informações de seus segmentos parte por área geográfica e parte por produtos e serviços. Observa-se, também na Tabela 5, que a evidenciação somente por áreas geográficas não está contemplada por nenhuma das empresas pesquisadas.

Portanto, oito empresas, do total da amostra de 33, não fazem qualquer tipo de evidenciação como estabelece a norma. Acrescenta-se que dessas oito, três não apresentam justificativa para tal descumprimento (Tabela 1).

\subsection{Quantidade de Segmentos Reportados}

Avaliou-se por esta pesquisa a quantidade de segmentos reportados em cada país, embora a norma IFRS 8 não determine uma quantidade mínima e máxima para isso, uma vez que devem ser os mesmos avaliados nos controles internos (IASB, 2006). A norma relata que quando os segmentos reportados forem acima de dez a companhia deve considerar que um limite prático foi atingido. (IASB, 2006). Foi observado pelos dados coletados que, dois e três segmentos prevalecem para as americanas, para quatro segmentos empresas americanas e brasileiras e para cinco segmentos para as empresas brasileiras. Nesta pesquisa as empresas que possuem apenas um segmento não evidenciaram as informações conforme IFRS 8 e, por isso, foram desconsideradas na análise. 
Também foi identificada a relação entre o nível de evidenciação das informações por segmento com o número de segmentos reportados. De fato, as companhias que alcançaram nível de evidenciação de $89 \%$ analisam seus negócios através de seis segmentos. Assim, é possível destacar que quanto maior o nível de evidenciação, maior o número de segmentos reportados. Pode-se sugerir que isso decorra do fato de que as companhias que possuem maior nível de evidenciação prefiram analisar as unidades de negócios de forma descentralizada, visando obter melhor compreensão sobre as operações.

\subsection{Itens com Menor Índice de Evidenciação}

Os dados da Tabela 6 apresentam os itens que tiveram índice de evidenciação abaixo de $50 \%$ e que foram mencionados por algumas companhias como não utilizadas pela administração para avaliar o desempenho dos segmentos.

Tabela 6 - Itens com Menor Índice de Evidenciação

\begin{tabular}{lcc}
\hline & Item de Divulgação & Total Amostra \\
\cline { 2 - 3 } & Empresas & \% \\
\hline Representatividade de clientes & 2 & 8 \\
Impostos sobre o lucro & 6 & 36 \\
Receitas e despesas financeiras & 9 & 36 \\
Conciliação dos passivos & 9 & 40 \\
Passivos do segmento & 10 & 40 \\
Resultados de equivalência patrimonial & 10 & 40 \\
\hline
\end{tabular}

Fonte: Dados da Pesquisa.

A norma IFRS 8 exige, de modo geral, que as informações dos segmentos sejam apresentadas da mesma forma como são utilizadas internamente para avaliar o desempenho do segmento. A norma relata ainda que se algumas informações não são preparadas para uso interno, não é necessária sua evidenciação caso tais informações não estejam disponíveis e o custo para desenvolvê-las for excessivo. (IASB, 2006).

\subsection{Relação do Índice de Eficiência de Ativos e o Grau de Evidenciação}

Buscou-se verificar se há relação entre o índice de eficiência das companhias e o grau de evidenciação em relação às informações por segmento. A utilização do índice de eficiência deu-se em função da dificuldade de avaliar apenas o tamanho do ativo, uma vez que as empresas da amostra operam com moedas diferentes e pela dificuldade de padronizá-las em uma única moeda.

Em função dessa dificuldade, utilizou-se o índice do giro do ativo (Vendas: Ativo médio), que indica a eficiência com que a entidade utiliza seus ativos para gerar vendas. Quanto mais elevado for o giro do ativo total, maior será a eficiência na utilização destes ativos. (Gitman, 2010). O índice de eficiência de cada companhia consta da Tabela 7. 
Tabela 7 - Índice de Eficiência e Pontuação

\begin{tabular}{|c|c|c|c|}
\hline Companhia & Nacionalidade & Índice de Eficiência & Pontuação \\
\hline Aurubis AG & Alemanha & 2,8293 & 13 \\
\hline Commercial Metals Company & EUA & 1,9601 & 14 \\
\hline Friedman Industries Inc & EUA & 1,5605 & 9 \\
\hline Worthington Industries Inc. & EUA & 1,4722 & 12 \\
\hline SKW Stahl Metallurgie Holding AG & Alemanha & 1,4504 & 17 \\
\hline United States Steel Corp. & EUA & 1,3754 & 12 \\
\hline Timkensteel Corp & EUA & 1,3707 & 12 \\
\hline Nucor Corporation & EUA & 1,3696 & 11 \\
\hline Steel Dynamics Inc. & EUA & 1,3222 & 13 \\
\hline ThyssenKrupp AG & Alemanha & 1,1579 & 17 \\
\hline Valmont Industries Inc. & EUA & 1,1344 & 13 \\
\hline Salzgitter AG & Alemanha & 1,0799 & 16 \\
\hline Mangels Industrial S.A. & Brasil & 1,0388 & 8 \\
\hline Carpenter Technology Corp. & EUA & 0,7317 & 13 \\
\hline Imerys & França & 0,7165 & 14 \\
\hline Gerdau S.A. & Brasil & 0,7018 & 18 \\
\hline Metalúrgica Gerdau S.A. & Brasil & 0,6989 & 18 \\
\hline Alcoa Inc. & EUA & 0,6537 & 15 \\
\hline SGL Carbon SE & Alemanha & 0,6316 & 12 \\
\hline Allegheny Technologies Inc. & EUA & 0,6266 & 13 \\
\hline Vallourec & França & 0,6152 & 15 \\
\hline Cia Ferro Ligas da Bahia - Ferbasa & Brasil & 0,5826 & 6 \\
\hline Tekno S.A. - Indústria e Comércio & Brasil & 0,5640 & 13 \\
\hline Usinas Sid. de Minas Gerais S. A. & Brasil & 0,3797 & 12 \\
\hline Cia Siderúrgica Nacional & Brasil & 0,3220 & 9 \\
\hline
\end{tabular}

Fonte: Dados da Pesquisa.

A verificação da existência ou não de relação entre o índice de eficiência (giro do ativo) e o grau de divulgação das informações deu-se por meio do coeficiente de correlação de Pearson. Tal coeficiente possibilita verificar se há uma relação linear entre essas variações, bem como a intensidade e a direção desta relação. (Larson \& Farber, 2010). Essa é mais uma medida de aferição da relação entre o porte das empresas e o nível de evidenciação delas por segmentos de negócio.

Os dados da pesquisa mostram que a empresa mais eficiente (a alemã Aurubis AG) não é a que apresenta o maior número de categorias de evidenciação. Com o mesmo número de categorias atendidas tem-se a americana Allegheny Technologies Inc., cujo índice de eficiência representa 
apenas $22 \%$ da alemã. A Figura 4 mostra a relação entre essas duas variáveis. Percebe-se concentração mais acentuada nas empresas com menor índice de eficiência. Se a alta eficiência significa maior atratividade de investidores, pode-se inferir que as menos eficientes têm mais dificuldades nessa atratividade e, em decorrência disso, desenvolve mais esforços de evidenciação para sensibilizar e atrair os investidores.

Figura 4 - Correlação entre o Grau de Eficiência e o Nível de Evidenciação

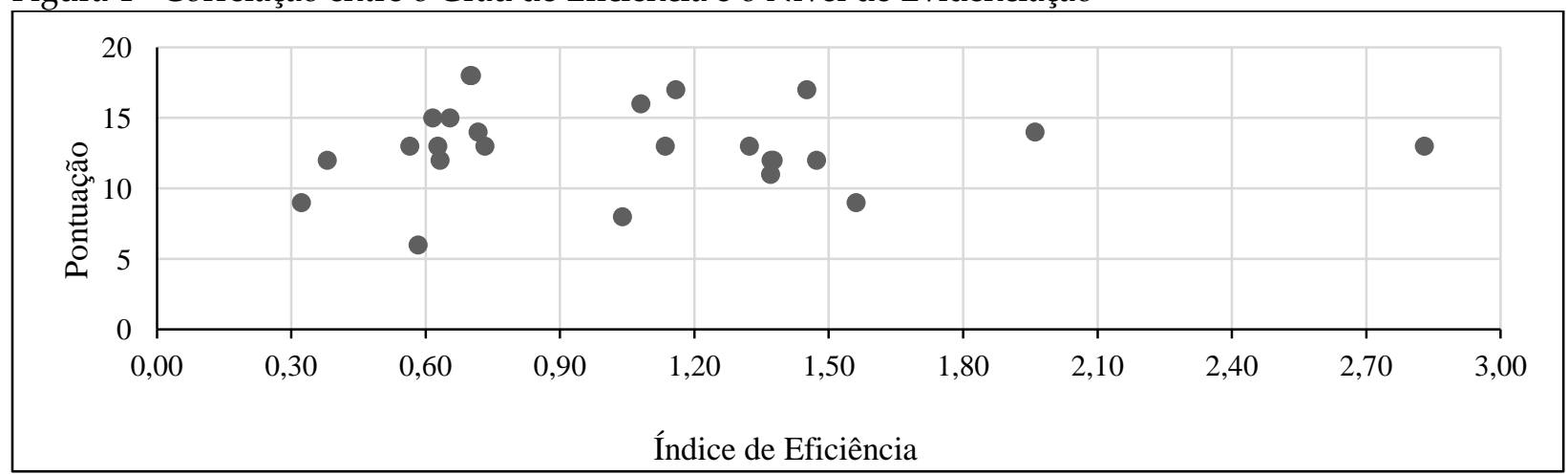

Fonte: Dados da Pesquisa.

NA Tabela 8 são apresentados os coeficientes de correlação por nacionalidade das empresas. O objetivo é analisar se há relação entre as variáveis de companhias de mesma nacionalidade.

Tabela 8 - Coeficiente de Correlação por País

\begin{tabular}{lc}
\hline \multicolumn{1}{c}{ Nacionalidade das Companhias } & Coeficiente de Correlação \\
\hline Alemãs & $-0,160$ \\
Brasileiras & 0,052 \\
Francesas & $-1,000$ \\
Norte-Americanas & $-0,387$ \\
Total da Amostra & $\mathbf{0 , 0 2 7}$
\end{tabular}

Fonte: Dados da Pesquisa.

Nota-se, em relação às companhias alemãs e norte-americanas, que há coeficiente de correlação negativos em -0,160 e -0,387, respectivamente, evidenciando, em geral, uma relação inversa e de baixa intensidade (Larson \& Farber, 2010). Desta forma, quanto maior o índice de eficiência, menor a quantidade de informações divulgadas pelas companhias, mas isso não ocorre com significativas dimensões.

As brasileiras não apresentaram relação entre o índice de eficiência e o grau de informações por segmento divulgadas, confirmado pelo reduzido coeficiente 0,052, próximo à zero. Deste modo, companhias com índices de eficiência semelhantes tiveram níveis diferentes de evidenciação das informações de seus segmentos de negócios.

Quanto às companhias francesas, o coeficiente atingiu a 1,000 negativo, indicando que há uma relação inversa e perfeita entre as variáveis. Assim, quanto maior o índice de eficiência, menor é o nível de evidenciação. Esse resultado corrobora o entendimento apresentado no parágrafo anterior à Figura 4. Ainda com relação às empresas francesas é preciso considerar que a baixa dimensão da amostra pode estar afetando tais dados. De outra parte, o significado atribuído a tais resultados corrobora os achados no estudo de Nunes, Kronemberg, Santos e Marques (2018), 
os quais concluíram que empresas mais competitivas tendem a utilizar menor nível de evidenciação por segmentos de negócio.

\subsection{Análise dos Pareceres de Auditoria}

Analisou-se o parecer de auditoria das 33 companhias, a fim de verificar se há alguma ressalva apontada quanto a adoção às normas internacionais de contabilidade e, principalmente, ao IFRS 8. A análise dos pareceres identifica que há predominância das quatro principais empresas do segmento. Entre elas, a Price Waterhouse Coopers foi a mais solicitada entre as empresas estudadas (11). Observa-se que três companhias não justificaram a falta de evidenciação das informações por segmento e nada foi comentado pelos auditores em seus respectivos pareceres.

As cinco companhias que justificaram a falta de evidenciação das informações por segmento comentaram possuir apenas um segmento. No entanto, a norma IFRS 8 determina que mesmo assim as companhias devem informar as receitas de cada produto e serviço, informações por área geográfica, ambas provenientes de clientes externos, e informações sobre principais clientes. (IASB, 2006). Constatou-se que as empresas de auditoria, em geral, não ressalvaram esse não cumprimento pelas empresas auditadas.

Como pode ser observado, as empresas de auditoria que não fizeram qualquer menção sobre a falta de evidenciação das informações a respeito de área geográfica e de principais clientes agiram de forma contrária ao que determina o IFRS 8.

\subsection{Discussão dos Resultados}

A discussão dos resultados da pesquisa não contempla a utilização de variáveis sobre os mercados e a realidade política e econômica dos países citados. Isso ocorre porque, mesmo reconhecendo os efeitos dessas variáveis, tal amplitude e abrangência está fora do escopo e objetivo do estudo.

Em relação ao quadro geral da evidenciação pelas empresas as alegações encontradas neste estudo, de que possuem apenas um segmento e seria repetitivo evidenciar por segmento, são as mesmas indicadas no estudo de Almeida et al. (2015) e por Aillón et al. (2013).

Sobre o nível de evidenciação das informações por segmento os resultados desta parte da pesquisa, Tabela 2, diferem daqueles encontrados por Oliveira et al. (2015), os quais identificaram que os itens mais evidenciados são: conciliação da receita, receitas de clientes, receita financeira, custo, despesa financeira e lucro líquido. O menor nível de evidenciação ocorre nas receitas provenientes de clientes do exterior. Em ambos os estudos se registrou o reduzido nível de divulgação da participação de clientes que detinham mais de $10 \%$ das vendas.

De forma geral há acentuada diferença entre os resultados das pesquisas de Silva e Pinheiro (2012), Mapurunga et al. (2014), Oliveira et al. (2015) e os deste estudo. De outra parte, há razoável similaridade em alguns indicadores específicos, como, por exemplo, evidenciação de passivos por segmento, próximo a 50\% das companhias de cada estudo. Outro elemento que merece destaque pela representatividade próxima é a evidenciação do lucro ou prejuízo por segmento. Destaca-se, ainda, que na maioria das categorias é perceptível uma melhora no nível de evidenciação, sugerindo que as empresas estão evoluindo no processo de divulgação de informações por segmentos, tendo em vista os resultados deste estudo em relação aos estudos anteriores.

Sobre a média das categorias evidenciadas neste estudo, Tabela 4, é superior àquela encontrada por Aillón et al. (2013), os quais identificaram em sua pesquisa que, em média, as empresas da amostra evidenciavam 9,1 das 19 categorias analisadas. Além disso, o máximo de categorias evidenciadas foram 17, enquanto os resultados desta pesquisa identificaram 18 categorias. Isso pode sugerir uma pequena melhora na divulgação das informações por segmento. 
Os resultados da análise quanto aos critérios de avaliação dos segmentos, corroboram os encontrados por Silva e Pinheiro (2012), Schvirck et al. (2013), Almeida et al. (2015) e Oliveira et al. (2015). A maioria das companhias evidencia as informações de seus segmentos por unidade de negócios, confirmando a predileção comentada por Frezatti, Rocha, Junqueira e Nascimento (2009), a respeito da gestão descentralizada por produtos e serviços. $\mathrm{O}$ alto índice de evidenciação pode ser justificado pela necessidade das companhias conhecerem os custos dos seus produtos e serviços e avaliarem a continuidade deles. Outro motivo, conforme argumenta Boscov (2009), é que as companhias evitam divulgar as informações por áreas geográficas para evitar práticas de dumping e por receio de exposição da organização.

Em relação à quantidade de segmentos reportados, os resultados encontrados assemelhamse aos encontrado por Schvirck et al. (2013), os quais constataram que a maioria das companhias avaliam seus negócios por meio de um, dois e três segmentos. Os resultados deste estudo são contrários àqueles encontrados por Oliveira et al. (2015), os quais identificaram que à medida que o número de segmentos aumenta, o nível de evidenciação diminui.

Tendo em vista o disposto pelo IASB, Franzen e Weibenberger (2015) comentam que há uma deficiência associada com o conceito de a evidenciação ser realizada em conformidade com os controles internos, o que pode refutar a suposição básica de que as informações utilizadas pela administração sempre representam as informações mais úteis para os investidores e outros usuários das informações das demonstrações contábeis.

A observação de Franzen e Weibenberger (2015) pode ser compreendida por meio dos dados apresentados na Tabela 6. Informações relevantes como receitas e despesas financeiras, passivos do segmento e representatividade de clientes não foram evidenciadas por não serem objetos de avaliação pela administração. No entanto, mesmo que não evidenciadas por grande parte das companhias, são informações que podem auxiliar a decisão de investidores e demais usuários das demonstrações contábeis.

Os resultados da Figura 4 corroboram os resultados encontrados por Oliveira et al. (2015), os quais verificaram se as companhias com maior retorno sobre seus ativos tiveram maior grau de evidenciação, constatando que aquelas com retorno acima da média do setor possuem menor nível de evidenciação das informações por segmento.

Em decorrência da recepção das normas IFRS 8 e SFAS 131, dadas pelo Pronunciamento CPC 22 (2009), a evidenciação de informações por segmento tornou-se uma obrigatoriedade das empresas dentro das condições estabelecidas (Nunes et al., 2018). Consequentemente, integra o conjunto de demonstrações oficiais que a atuação da auditoria independente deve contemplar. Diante disso, a ausência de apontamentos específicos nos relatórios e pareceres de auditoria, abordada no tópico 4.8 deste estudo, evidencia um descumprimento que precisa ser mais bem estudado. Isso é necessário tendo em vista a qualidade e confiabilidade quanto à transparência e evidenciação que se espera das publicações aos diversos usuários das informações contábeis (Hendriksen \& Van Breda, 1999).

\section{CONSIDERAÇÕES FINAIS}

Este estudo teve como objetivo verificar o nível de evidenciação das informações por segmento nas demonstrações contábeis de companhias alemãs, brasileiras, francesas e norteamericanas que atuam no ramo de siderurgia e metalurgia, inclusive de forma comparativa às brasileiras. Para atingir este objetivo analisaram-se as informações sobre as unidades de negócios evidenciadas nas notas explicativas, constantes nas demonstrações contábeis das respectivas companhias.

Observou-se que nenhuma companhia apresentou a totalidade das informações avaliadas por meio das exigências do IFRS 8. Quanto às empresas brasileiras, observa-se, comparativamente 
às demais, que a primeira classificada se encontra em $13^{\text {o }}$ lugar de um total efetivo de 25 participantes. Duas outras empresas situam-se em $16^{\circ}$ e $17^{\circ}$ lugares. As quatro restantes são as últimas classificadas. Mesmo considerando-se a limitação de análise provocada pelo desbalanceamento da amostra de empresas por país, deve-se reconhecer que, no geral, as brasileiras têm ainda um largo espaço para melhorias.

Quanto ao não atendimento de categorias de evidenciação estabelecidas na norma, é relevante destacar que não há, por parte das companhias independentes de auditoria, qualquer ressalva quanto à falta de divulgação das informações por segmento ou a falta de divulgação de informações que são utilizadas internamente. Ao contrário, a maioria das companhias de auditoria relatou que as demonstrações contábeis estão em conformidade com as normas internacionais de contabilidade.

Isso conduz ao entendimento de que há ainda um bom espaço a ser cumprido pelas empresas na evidenciação de suas informações por segmentos de negócio, assim como das empresas de auditoria em retratar nos respectivos pareceres o grau em que a norma está sendo atendida. Essa pode ser uma informação relevante para mercado.

A contribuição do estudo reflete-se na sinalização dada ao mercado a respeito do grau de evidenciação das empresas, destacando aquelas categorias mais presentes dentre aquelas não atendidas, as quais podem ser críticas no processo decisório de analistas e investidores.

Quanto ao meio acadêmico, a contribuição mais explícita refere-se ao conteúdo das disciplinas de auditoria e evidenciação de informações quanto aos fundamentos conceituais da norma e respectivos procedimentos práticos para evidenciação (pelas empresas informantes) e serviços de revisões (pelas empresas de auditoria) mais amplos sobre as categorias de informação.

As principais limitações do estudo decorrem da característica da amostra. Dada a centralização em um segmento específico de negócio, no caso a siderurgia e metalurgia, desbalanceamento na composição da amostra entre os países participantes podem ocorrer. Afinal, nem toda atividade de negócio está presente na mesma dimensão entre os países. Apesar da adoção de médias ponderadas atenuar o efeito do peso relativo das diferentes quantidades de empresas participantes, quando possível, outros efeitos podem ocorrer. Assim, a adoção de amostras mais parelhas, mesmo que em segmentos diferenciados, podem reduzir os impactos do problema amostral.

Todo trabalho, durante sua execução, descortina oportunidades de novas pesquisas, inclusive em função das naturais limitações de foco, escopo, amostra e outras possibilidades. Como sugestão de estudos futuros, e considerando-se que já há material considerável sobre o tema, recomenda-se cinco tipos de trabalho: (1) consolidação dos diversos resultados apresentados pelas pesquisas, viabilizando-se assim um maior domínio da situação geral; (2) identificação das principais categorias não informadas, pesquisar junto às empresas informantes as possíveis causas dessa ausência de informação; (3) realizar estudos de caso em profundidade a fim de melhor diagnosticar anormalidades identificadas em relação à norma por pesquisas do tipo levantamento; (4) realizar pesquisas junto a empresas de auditoria, a fim de discutir a propriedade de citar nos pareceres as ausências encontradas; (5) desenvolver estudos com maior leque de países, incluindo variáveis que possibilitem identificar impactos provocados por realidades distintas, tais como de mercado, estrutura política, econômica e regulações específicas, Entende-se que com esses estudos ter-se-á material suficiente para alavancar conhecimentos acadêmicos e profissionais sobre o tema. 


\section{REFERÊNCIAS}

Aillón, H. S., Silva, J. O., Pinzan, A.F. \& Wuerges, A. F. E. (2013). Análise das informações por segmento: divulgação de informações gerenciais pelas empresas brasileiras. Revista Contemporânea de Contabilidade, 10(19), 33-48.

Almeida, S. R., Silva, R. P.A., Alves, K. R. C. P. \& Oliveira, K. P. S. (2015). Informação por segmento: aspectos informativos e gerenciais nas entidades do setor de construção civil listadas na BM\&FBovespa. Qualitas Revista Eletrônica, 16(2), 73-90.

BMF\&Bovespa. Bolsa de Mercadorias \& Futuros Bovespa S.A. (2016). Empresas listadas, 2016. Recuperado em 20 fev. 2016, de: http://www.bmfbovespa.com.br/pt_br/produtos/listados-avista-e-derivativos/renda-variavel/empresas-listadas.htm

Borse Frankfurt. (2016). Companies information. Frankfut. Recuperado em 20 fev. 2016, de: http://www.boerse-frankfurt.de/

Boscov, C. P. (2009). O enfoque gerencial na divulgação de informações por segmento. Dissertação de Mestrado, Universidade de São Paulo, São Paulo, Brasil.

Comitê de Pronunciamentos Contábeis (CPC). (2009). Pronunciamento Técnico CPC 22: informações por segmento. Brasília, DF. Recuperado em 15 set. 2015, de http://static.cpc.mediagroup.com.br/Documentos/292_CPC_22_rev\%2008.pdf

Conselho Federal de Contabilidade (CFC). (2005). Resolução CFC № 1.055/05. Cria o Comitê de Pronunciamentos Contábeis (CPC). Brasília, DF, 7 out. Recuperado em 2 nov. 2015, de: www.cfc.org.br/sisweb/sre/docs/RES_1055.doc

Cruz, A. P.C.; Machado, E.A.; Oleiro, W.N. \& Carvalho, L.N. (2011). Empresas brasileiras do novo mercado e suas práticas de evidenciação voluntária de informações por segmento. Anais do Encontro da Associação Nacional de Pós-graduação e Pesquisa em Contabilidade, Vitória, ES, Brasil, 5.

Ernest \& Young \& Fipecafi. (2009). Manual das normas internacionais de contabilidade. São Paulo: Atlas.

Euronext Paris. (2016). Company Information. Paris. Recuperado em 5 mar. 2016, de: http://www.boursedeparis.fr/

Fajardo, C. L. (2007). The move towards convergence of accounting standards worldwide. Cambridge: Journal of American Academy of Busines, 12(1), 57-61.

Fath, K. T., Gauski, D., Oro, I. M. \& Sott, V. R. (2015). Informações por segmento de companhias brasileiras da BM\&FBOVESPA. Anais do Congresso Brasileiro de Custos, Foz do Iguaçu, CBC, 22.

Ferreira, E. M. (2011). Evidenciação de informações por segmento de negócio: uma análise das companhias integradas de óleo e gás listadas na NYSE (Bolsa de Valores de Nova York). Dissertação de Mestrado, Universidade de Brasília, Universidade da Paraíba e Universidade do Rio Grande do Norte. Rio Grande do Norte, Brasil.

Ferreira, V. J., Souza, F. A., Guerra, J. O. \& Mariano, F. O. (2018). Evidenciação do CPC 22 informações por segmento: um comparativo entre as empresas de maiores lucros e prejuízos listadas na revista Exame. Pensar Acadêmico, 16(1), 148-165.

Franzen, N. \& Weibenberger, B. E. (2015). The adoption of IFRS 8 - no headway made? Evidence from segment reporting practices in Germany. Journal of Applied Accounting Research, 16(1), 88113. 
Frezatti, F., Rocha, W., Junqueira, E. \& Nascimento, A.R. (2009). Controle gerencial: uma abordagem da contabilidade gerencial no contexto econômico, comportamental e sociológico. São Paulo: Atlas.

Gil, A. C. Como elaborar projetos de pesquisa. (2010). 5. ed. São Paulo: Atlas.

Gitman, L. J. Princípios de administração financeira. 12. ed. São Paulo: Pearson, 2010.

Hendriksen, E.S., \& Van Breda, M.F. (1999). Teoria da contabilidade. São Paulo: Atlas.

International Monetary Fund (IMF). (2015). Word Economic Outlook: Uneven Growth: Short-and Long- Term Factors: Washington. Recuperado em 30 out. 2015, de: http://www.imf.org/external/pubs/ft/weo/2015/01/pdf/text.pdf

International Accounting Standards Board (IASB). (2006). International Financial Reporting Standard 8. London.

Kang, H. \& Gray, S. J. (2013). Segment reporting practices in Australia: has IFRS 8 made a difference? Australian Accounting Review, 23(66), 232-243.

Larson, R. \& Farber, B. (2010). Estatística aplicada. São Paulo: Pearson.

Lopes, I. F. \& Beuren, I. M. (2017). Evidenciação da informação contábil: uma retrospectiva das pesquisas socializadas no congresso Anpcont. Revista Evidenciação Contábil e Finanças, 6(2), 5880.

Mapurunga, P.V. R.; Ponte, V. M. R. \& Holanda, A. P. (2014). Fatores explicativos da aderência das firmas brasileiras ao disclosure relativo às informações por segmento. Enfoque: Reflexão Contábil, 33(1), 53-69.

Marconi, M. A. \& Lakatos, E. M. (2010). Fundamentos da metodologia científica. 7. ed. São Paulo: Atlas.

Martins, G. A. \& Theóphilo, C. R. (2007). Metodologia da investigação científica para ciências sociais aplicadas. São Paulo: Atlas.

Mourad, N. A. (2009). IFRS 8: segmentos operacionais: contabilidade internacional: Internacional Financial Reporting Standards - IFRS. São Paulo: Atlas.

Nichols, N. B., Street, D. L. \& Cereola, S. J. (2012). An analysis of the impact of adopting IFRS 8 on the segment disclosures of European blue chip companies. Journal of International Accounting, Auditing and Taxation, 21(2), 67-90.

Nunes, P. P., Kronemberg, R. A., Santos, O. M., Marques, J. A. V. C. (2018). Divulgação de informações por segmento das companhias de óleo \& gás listadas na SEC. Revista Mineira de Contabilidade, 19(1), 1-17.

Oliveira, N. E., Costa, P.S. \& Ávila, J. R. M. S. (2015). Análise relação entre a divulgação de informações por segmento e a competitividade. Pensar Contábil, 17(64), 56-64.

Oliveira, S. L. (1999). Tratado de metodologia científica: projetos de pesquisa, TGI, TCC, monografias, dissertações e teses. 2. ed. São Paulo: Pioneira.

Pacter, P. (2016). Pocket guide to IFRS standards. London: IFRS Publications Dept.

Parlamento Europeu. (2002). Conselho da UE Regulamento (CE) no 1606/2002 do parlamento europeu e do conselho relativo de 19 de julho de 2002 à aplicação das normas internacionais de contabilidade. Jornal Oficial das Comunidades Europeias, n. 1.

Pinheiro, V. A. A. \& Boscov, C. P. (2015). Análise de informações por segmento das empresas premiadas pela Anefac/fipecafi/Serasa 2013. ConTexto, 15(29), 96-112.

Schvirck, E., Lunkes, R. J. \& Gasparetto, V. (2013). Divulgação das informações por segmento: panorama da aplicação do CPC 22. Revista de Educação e Pesquisa em Contabilidade, 7(2), 131-146. 
Silva, F. A. \& Pinheiro, L. E. T. P. (2012). Estágio atual de evidenciação e fatores que influenciam o disclosure de informações por segmentos por empresas brasileiras. Revista Contabilidade $e$ Controladoria, 4(3), 78-94.

Suzart, J.A.S. (2016). Índices de evidenciação: quando um mais zero não é igual a um. Contabilometria, 3(1), 52-70.

Verrecchia, R.E. (2001). Essays on disclosure. Journal of Accounting and Economics, 32(1), 97-180.

Weschenfelder, C. \& Mazzioni, S. (2014). Informações por segmento: análise do nível de evidenciação das companhias listadas no novo mercado. Revista Catarinense da Ciência Contábil, 13(39), 21-33.

Wordsteel Association. (2015). Indirect trade in steel Brussels, mar. 